\title{
James Newman: Playing with videogames. New York: Routledge. 2008
}

\section{Hanna Wirman}

MedieKultur 2010, 48, 152-155

Published by SMID | Society of Media researchers In Denmark | www.smid.dk The online version of this text can be found open access at www.mediekultur.dk

James Newman's book Playing with Videogames is accurately as well as playfully entitled. The book documents a wide range of player creativity and productivity that situates somewhat outside but is nevertheless inherently linked to the actual playing of videogames. Instead of the gameplay itself, the book is concerned with activities that go beyond it. The fans or gamers involved in such practices are not, as Newman notes, but a minority of players, whereas the "outputs of their work exist within and even create wider cultures, communities and rich contexts for criticism, review and play" (Newman, 2008, p. 152). Thus, the book builds on the "playing with videogames" as a social and cultural practice consisting of different player hierarchies. It also presents the plasticity of videogames in regard to fan reworkings as well as the ways in which fan texts affect and inform later play experiences.

Playing with Videogames is divided into three parts, each approaching player engagement from a different angle. Part 1: Videogames as representational systems considers cases of player productivity that better correspond to those familiar among earlier media and that concentrate on, although are not limited to, the narrative and "textual" level of games instead of simulation and structure, which are examined in Part 2: Videogames as configurative performances. For Newman, "walkthrough writing [as broadly discussed in Part 2] largely eschews discussion of the videogame as a representational system and instead treats it as a simulation model with inputs and outputs as a series of complex mathematical models, logical systems and programming loops" (p. 119). While various aspects of the technology of videogames are discussed throughout the book, Part 3: Videogames as technology con- 
centrates on fan texts, whose authors attempt to master games by means of a high level of technical competence, changing the games' code by hacking them. What is left out of the book, due to the focus on everyday player productivity, are the explicitly tactical or political uses of game technology.

This structure of the book leads to a raw categorisation of player-productivity in which fan fiction and fan art are situated within the first group (Part 1), texts that centre around knowledge of the inner workings of game simulation, such as walkthroughs, "superplay" and speed running, are in the second group (Part 2) and game hardware and software modifications are in the third group (Part 3). By introducing these varying sorts of productive and creative activities and the in-built workings of community and sociality in them, Newman successfully shows that game play can also be, and often is, a productive, creative, social and teaching endeavour. The book thus responds to a popular concept that groups all games together and suggests gameplay is an isolating and damaging activity.

As such, the book seems to be targeted at those people not yet convinced of the value of computer games and to offer an alternative to the media panic surrounding games. Newman's point regarding how "videogames offer a complex and varied suite of materials for gamers that encourage flexible and creative play, talk, discussion and the production of supporting texts that are exchanged and valued within the myriad fan communities" (p. 15) is clearly argued by the examples given. Probably the best documented and most extensive (also in pages) part of the book is the analysis of texts that are created in order to make gameplay more effective - walkthroughs, game guides and FAQs - in Part 2. This also makes Part 2 particularly clear and effective in its concentration on practices that are clearly related to and inform each other.

What thus characterises the book is a strong emphasis on the description of dozens of cases of player productivity/creativity instead of attempts to theorise the interrelations or shared cultural background behind these forms of user engagement. This is understandable for an introduction, not to mention deeper analyses, as many of the phenomena introduced are not available in earlier literature. Arguably, Newman is one of the few individuals who has paid attention to the importance of game magazines in sustaining player communities, for example.

However, in many cases the discussion could have been further developed by presenting studies about fandoms and users of other media. It is somewhat surprising that references to cultural and media studies' accounts on active audiences, fans and resistance are not thoroughly described. Instead, Newman draws on earlier textbooks on game cultures, especially those by Dovey and Kennedy $(2006)^{1}$ and Burn and Schott (2006) ${ }^{2}$. Research in the emerging field of game studies is nevertheless discussed where possible, especially in the chapters that consider mod-making (albeit the chapter on sound lacks the relevant references available). Writings of fans themselves and other quotes from game related online forums are numerous. Such a reference structure for a book can be read as a statement recalling research that centres on the specificity of the computer game medium instead of 
considering games as "just another popular media". In the field of game studies, Newman's book is situated among the works that draw on the wide-ranging everyday use of games rather than on their structural or formal elements. While many accounts in the book discuss game narratives, it is done from the player's perspective, not imposing theories of narratives over the structure of the games.

Whereas the book goes into great detail in documenting individual practices, many theoretical questions, especially those related to fandom, are left unanswered: What is the "textual" level of games? How do the examples given relate to the idea of fans as critical and "special" members of the audience? Which kind of theoretical accounts would elaborate the way in which these practices can be seen simultaneously resistant and exploitative? What forms of player productivity are unique for game cultures and which ones have counterparts in earlier media? The book would also have benefitted from a closer analysis of the fan texts' interconnectedness with the actual sessions of play and from explorations on whether there are significant differences between fan texts in this regard. While these are just questions that the reading of the book raises, more problematic is the use of some terminology. "Collective intelligence" and "fandom" are discussed without critique and without definitions. Because the concept of fandom is not unpacked, the reader may wonder whether "non-fannish" activities of mere playing remain destructive. In addition, concepts more specific to game culture such as "superplay" and "gamer" are used in a way that differs from their use in game studies in general. What Newman proposes as superplay is often referred to as "power gaming". Also the use of the term "gamer", which is suggested as an umbrella term for player, otaku and the like, differs from its typical use in game studies. However, such confusion may not be the result of the author's ignorance, but rather a signifier of the fluidity of terms, both within academia and in game cultures, as well as of their different uses among different game subcultures.

Fundamentally, the book promises to document the "richly productive, playful and social culture of videogaming", celebrating the sometimes resistant, contested and often innovative works of game fans. This makes the book an enjoyable read as the author himself seems to posses great insight and enthusiasm into the subcultural practices introduced, although no mention on the methods through which such knowledge was gathered is made. Without documentation on how the material was gathered, statements such as "there is a true sense of collaboration" may seem too bold.

The examples offered in the book assure the reader of the shared knowledge and intelligence of players and that such knowledge is sometimes greater than that of the games' developers. Fans' interest in knowing everything about the original games lies behind their productivity and the existing material of games informs their creativity. This relationship between the games industry and players' texts is considered, although not very systematically, throughout the book. Newman proposes that whereas the games industry is extraordinarily welcoming towards the forms of fan fiction (Part 1 ), the practices documented in Part 3, which also require the highest level of technical competence, are those that most 
visibly raise legal and economic issues. Further exposing the conflict of interest, the book shows how some forms of appropriating games, homebrew hardware for instance, are forcefully tackled by game developers, though many other player creations are accepted where they give longevity, new ideas and extended interest among game communities to commercial products.

Newman's final conclusion draws on recent examples of "Game 3.0" phenomena, where the productivity, creativity and sociality of players reaches a degree so sustainable that it is possible to build new game titles upon these aspects of playing with videogames. The last chapter of the book looks at recent games such as Little Big Planet, which thrive on player-created levels and other parts of the game. The extent to which players are invited to collaborate with game developers and the nature of this work pushes Newman to call into question the entire "gameness" of these new software services and toolkits. By briefly looking at what kinds of games we will probably be playing in the future, Newman ends his book with the same forward looking way he has, throughout the book, suggested the entire game development, and the player co-creativity alongside it, works.

\section{Notes}

1. Dovey, J., \& Kennedy, H.W. (2006). Game Cultures: Computer Games as New Media. Maidenhead: Open University Press.

2. Burn, A., \& Schott, G. (Eds.) (2006) Computer Games: Text, Narrative and Play. Cambridge: Polity Press.

Hanna Wirman

Ph.D. Student

Faculty of Creative Arts

University of the West of England, England

hanna.wirman@uwe.ac.uk 